\title{
Management of infrastructure's safety under the influence of normative provisions
}

\author{
P. Ntzeremes, K. Kirytopoulos \& I. Tatsiopoulos \\ School of Mechanical Engineering, \\ National Technical University of Athens, Greece
}

\begin{abstract}
Road tunnels, as any large civil infrastructure, must be designed taking into account all hazards in order to sustain an acceptable level of safety in the course of public servicing. Therefore, road tunnel management is oriented at protecting tunnels from fires, because such events fit into the general disaster management area due to their impacts on transportation systems. After the horrendous accidents that arose in Europe at the end of the 90s, e.g. Mont Blanc, the new legislation integrated risk assessment in order to enhance the process of ensuring a minimum level of safety in all road tunnels of the trans-European network. However, the variety of risk assessment methods, each Member State adopted, does not guarantee the same level of safety in all road tunnels. This paper aims to showcase this fact through a deductive approach by implementing two assessment methods in the same tunnel fulfilling Directive 2004/54/EC's requirements. These methods are the Greek and the French one, which beyond their common points, also bear interesting differences. Having compared the theoretical part, a fire scenario is investigated with the aid of the software Camatt 2.0. The results indicate that even a small difference in a standardized parameter of the method is capable of evaluating the same tunnel differently in regard to safety. One would expect that since the trans-European network is regarded as a common infrastructure, a common approach would also be established in risk assessment so that authorities and safety analysts of different Member States would come up with the same results. This paper contributes in raising this issue and creating momentum for the beginning of relevant initiatives.

Keywords: road tunnels, risk assessment, safety, tunnel fire, Greece, France.
\end{abstract}




\section{Introduction}

The serious accidents in the Mont Blanc (1999), Tauern (1999) and St. Gotthard (2001) road tunnels cost the lives of 39, 12 and 11 people, respectively. In addition, extended destruction in their facilities and also subsequent economic loss were recorded $[1,2]$. These tragedies were the determining factor that led to the imposition of a renewed legislation in the European Union. The result was the introduction of Directive 2004/54/EC, which provides the Member States with the minimum infrastructure and equipment requirements for the safety of their road tunnels [3]. The directive's main goal was to harmonize all European countries in a common context and contribute to a higher standard level of safety for road tunnels belonging to the trans-European road network.

Under the new framework, all Member States have developed and imposed new regulations according to the Directive 2004/54/EU's requirements including risk assessment methods, as well. Despite the existence of common principles both in the Directive and in risk assessment framework, many internal factors of the framework with greater or lesser importance are still decided by the authorities of each Member State in a different way [4, 5]. Therefore, road tunnels' level of safety with exactly the same characteristics could diverge among Member States because of the differences in countries' normative provisions.

The aim of this paper is to investigate the discrepancies that arise on the estimated level of safety of road tunnels. In order to achieve that, a comparison analysis is undertaken between two different regulations, the Greek and the French one, which besides many similarities, from their implementation on the same road tunnel reveal a difference in the estimated level of safety.

\section{Review on risk assessments methods}

Being complex systems, road tunnels not only do they need to fulfill all regulative requirements, but also need to be studied with a risk-based approach in order to examine some specific accidents and observe possible residual risks [5] while taking into account their inherent attributes [6].

The general framework of the risk assessment process for road tunnels in operation proposed by the World Road Association, has been adopted by the regulations of the majority of EU Member States [4]. Its basic steps are: (a) risk analysis, (b) risk evaluation and (c) risk reduction.

However, the presence of these principles does not seem to be enough. An overview of the existing risk assessment methods provides the potentiality of their categorization in respect to three basic axes: (a) the type of risk approach (systemic vs. scenario-based approach), (b) the type of transported goods (dangerous vs. non-dangerous goods) and (c) the type of method used (quantitative vs. qualitative methods). based on these axes, difficulties arise for their harmonization. For instance, a system-based approach, which gives a risk estimation for all relevant scenarios and because of that needs a large sum of data could not be compared with a scenario-based approach, which takes into account a subset of relevant scenarios, even if the other axes are exactly the same. Moreover, the straight 
classification of a method often becomes complicated as one method could use elements of different parts of an axis. A typical example of that is that the majority of the methods used tends to be named as semi-quantitative.

Placed next to the difficulties caused by axes categorization, there are also those arisen of the different key parameters in the normative provisions of each EU Member State. These parameters are related to system's elements, which are: (a) vehicles, (b) users, (c) infrastructure, (d) facilities, (e) transportation management, (f) working personnel, regulatory as well as emergency and (g) special features of crucial events (e.g. fire) [4].

Focusing on exploration of the combination of the aforementioned differences, two different risk assessment methods, the French [7] and the Greek [8] one, are selected and applied on a reference case. The decision is not arbitrary. Although these two methods have great similarity, when they are implemented in the same road tunnel they give rise to discrepancies big enough to change the estimated level of tunnel safety.

\section{Research method}

In order to achieve the aim of this research endeavor a deductive approach is adopted. This kind of approach can enable users in challenging an existing theory and providing a source of research questions and answers [9].

The deductive research process follows the path from theory to data. By the term Theory we regard the whole set of legislation that governs risk assessment in road tunnels. The main Hypothesis is that:

H0: Different regulations among countries lead to approximately the same results on the estimated level of safety of road tunnels.

At the Observation stage a simulated experiment is carried out that compares an indicative road tunnel fulfilling the requirements of the two national risk assessment methods. Initially, methods are compared in order to reveal their similarities and also to identify their dissimilarities so that a quantitative data analysis can be carried out in a scenario-based accident including fire in a vulnerable point of the tunnel. In the end, at the Conclusion stage, the differences in estimated level of safety are investigated.

\section{The French vs. the Greek assessment method}

Both countries conform to the new European framework for advancing road tunnels' level of safety by imposing new regulations. France designed a risk assessment method [7] including it in its safety documentation guide for all road tunnels longer than $300 \mathrm{~m}$, in year 2003. Greece imposed an equivalent method [8] for all road tunnels longer than $500 \mathrm{~m}$, in year 2011. General purpose of both methods was to contribute in designing emergency response plans. 


\subsection{Theoretical comparison of the two methods}

Concerning their classification based on the basic axes, the two methods have the following characteristics. Both are scenario-based, as they investigate a subset of accident scenarios. Furthermore, both adopt a quantitative approach because they use quantitative data across in almost every step. Regarding the kind of transported goods through them, both methods do not deal with dangerous goods, as the examination of dangerous goods is subjected to other regulations.

But, on a deeper examination, some important differences arise. Initially, it is the definition of the reference conditions. In the Greek method it is defined that the tunnel has to adopt all the prerequisites of Directive 2004/54/EU's reference tunnel. On the contrary, French method designates the reference conditions which the tunnel should have when opens to traffic or when the safety upgrade is completed.

Furthermore, difference exists in the way of introducing accident scenarios. In both methods, the purpose of their use is to propose possible corrective solutions to the reference conditions without total redesign of the system and to contribute to the design of emergency response plans. But in the French method it is defined that the accident scenario starts from the trigger of the crucial event, when in the Greek method accident scenarios are approached with the full bow-tie model (Hazards - Trigger Event - Consequences).

Last but not least, differences also pertain to the constant default values of the two methods. Both methods are provided with a number of standardized fire scenarios as well as some standardized thresholds in order to assess users' behavior, (i.e. users' perception, moving velocities, calculation of Fractional Effective Dose), infrastructure durability and resistance during a fire accident, which are not the same.

\subsection{Indicative case}

\subsubsection{Case description}

A reference case rural road tunnel is selected. In Table 1 its special attributes are reported. The stage of conducting the assessment is considered just before tunnel is to be given in operation.

The risk assessment is conducted for an accident scenario involving an outbreak of fire by an HGV without carrying dangerous goods in the middle of the tunnel. The fire scenario that is implemented is the 7th and the 9th standardized scenarios of Greek and French methods, respectively, which has the following parameters: Involvement in cause of a fire of one HGV with HRRmax=100MW. The difference is on the time in which fire of standardized scenarios reaches its maximum Heat Release Rate (HRRmax). This time is in 5 minutes for the Greek method and in 10 minutes for the French one.

Due to the shape of the tunnel (average height in portals and two-lane tunnel), both methods require a one-dimensional analysis of tunnel air flows in order to describe the changes in air conditions due to the fire. This part is conducted with the aid of Camatt 2.0 software, which is a CFD tool developed and supported by 
CETU according to French regulations and data and which can also be used by any other country for similar purposes [10].

Table 1: Road tunnel attributes.

\begin{tabular}{|c|c|c|}
\hline \multirow{6}{*}{$\begin{array}{l}\text { Designing features of } \\
\text { the tunnel }\end{array}$} & One dimension - single sector & \\
\hline & Total length & $2.700 \mathrm{~m}$ \\
\hline & Slope & $-1.5 \%$ \\
\hline & Number of exit doors & 6 \\
\hline & Number of traffic interruptions & 7 \\
\hline & $\begin{array}{l}\text { Starting time of traffic lights after the } \\
\text { ignition of the fire }\end{array}$ & $5 \mathrm{~min}$ \\
\hline \multirow{4}{*}{$\begin{array}{l}\text { System of mechanical } \\
\text { ventilation }\end{array}$} & Number of jet-fan-array & $8+1$ (backup) \\
\hline & $\begin{array}{c}\text { Number of jet fans making up the } \\
\text { array }\end{array}$ & 2 \\
\hline & Progressive function & \\
\hline & $\begin{array}{l}\text { Starting time of the system after the } \\
\text { ignition of fire }\end{array}$ & $2 \min$ \\
\hline $\begin{array}{c}\text { Pressure difference } \\
\text { between tunnel portals }\end{array}$ & $\begin{array}{l}95 \% \text { of max velocity based on local } \\
\text { estimations regardless direction }\end{array}$ & $28 \mathrm{~Pa}$ \\
\hline \multirow{2}{*}{$\begin{array}{l}\text { Environmental } \\
\text { conditions }\end{array}$} & Temperature & $12^{\circ} \mathrm{C}$ \\
\hline & Altitude & $600 \mathrm{~m}$ \\
\hline \multirow[t]{2}{*}{ Transporting conditions } & Vehicle flux & $55 \mathrm{veh} . / \mathrm{hr}$. \\
\hline & Proportion of HGVs & $30 \%$ \\
\hline
\end{tabular}

\subsubsection{Risk assessment's results}

From the analysis the opacity and the temperature diagrams are derived for the French and the Greek method, respectively (figs 1-4). Initially, the first serious

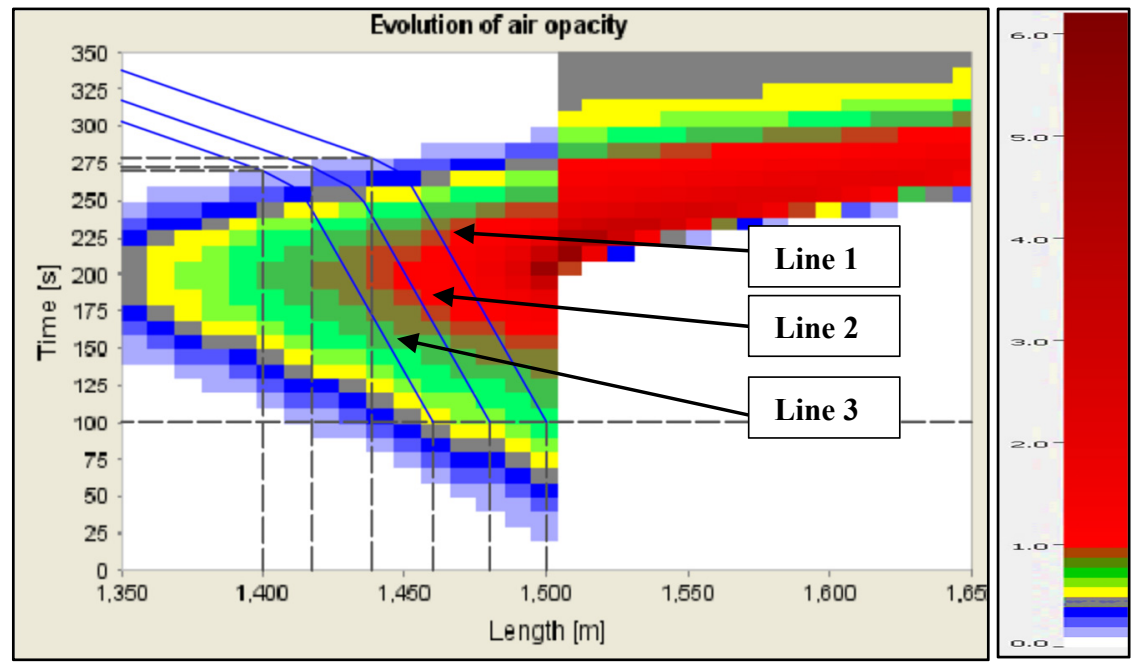

Figure 1: Smoke environment along with escape routes of trapped users according to the French method. 


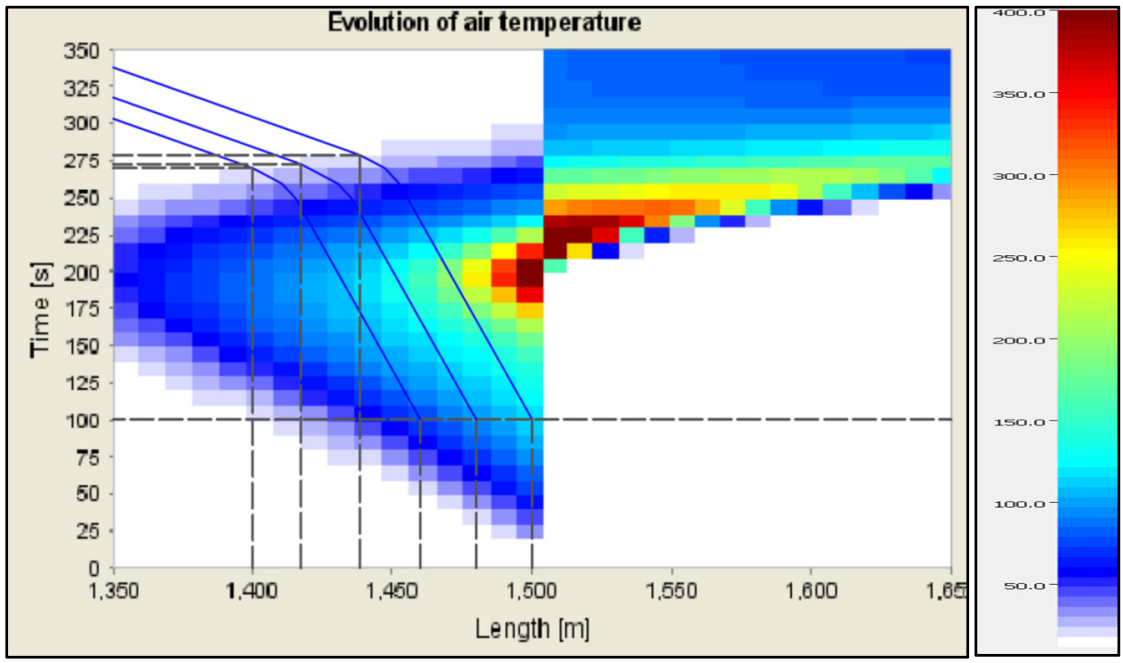

Figure 2: Fire environment along with escape routes of trapped users, according to the French method.
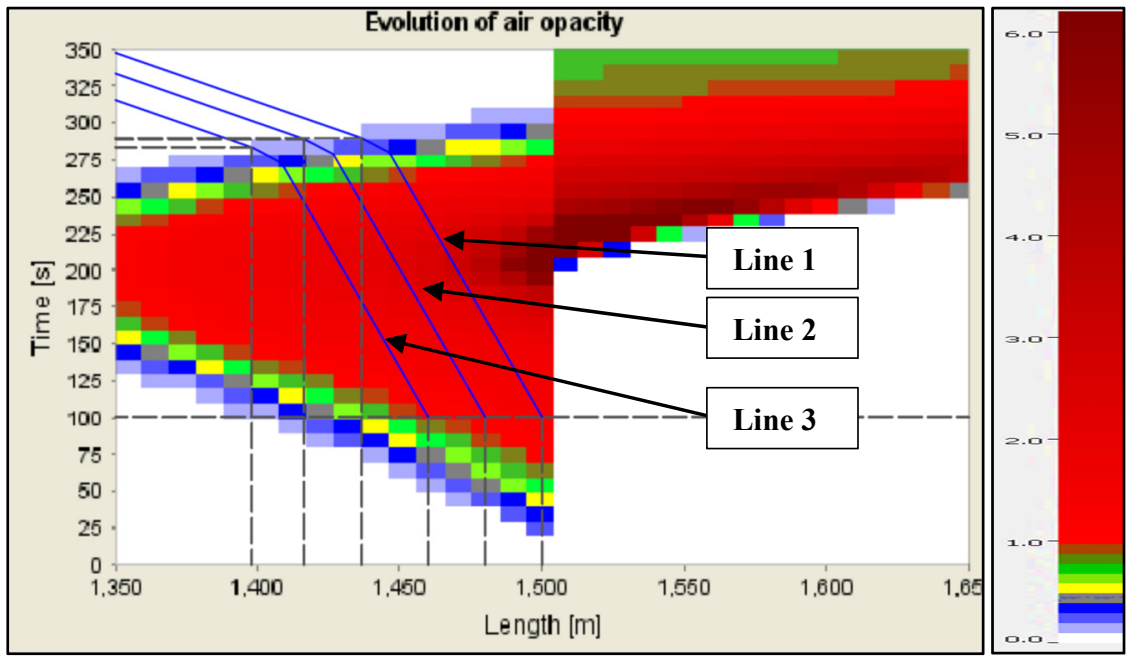

Figure 3: Smoke environment along with escape routes of trapped users according to the Greek method.

conclusion is the significant increase of air opacity along with the air temperature in Greek method, which are depicted in figs 3 and 4 in contrast with the French one in figs 1 and 2.

The reason for this outcome is in the different fire standardization of the two methods. Although both methods have the same HRRmax, the 5-minute divergence between fires' standardization in which this rate is achieved, causes an 


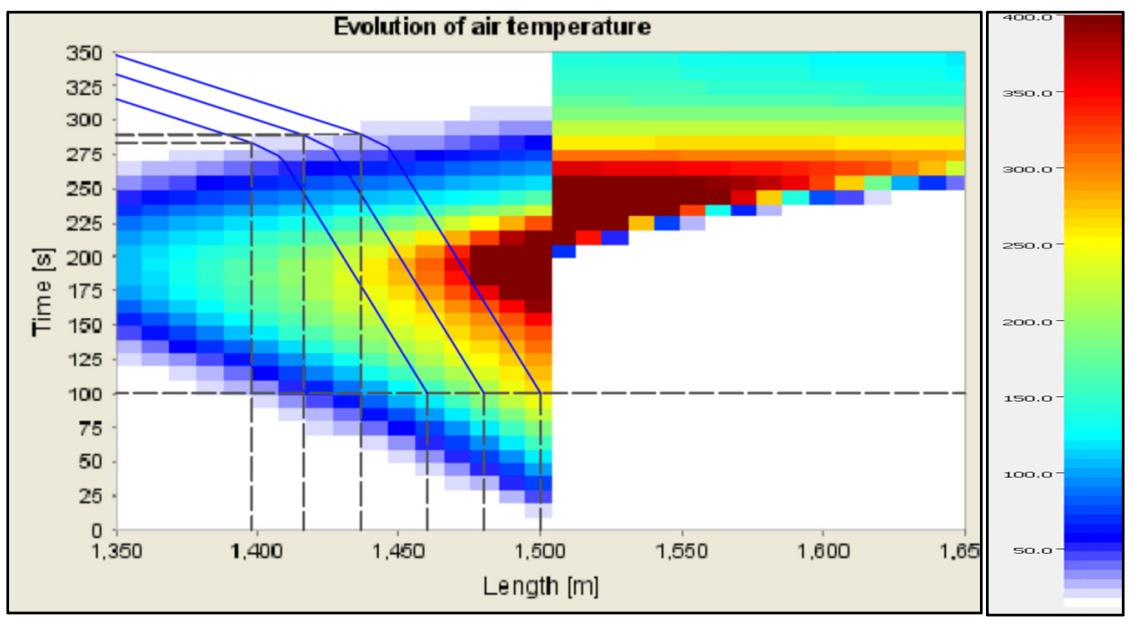

Figure 4: Smoke environment along with escape routes of trapped users according to the Greek method.

accelerating evolution of fire which results to faster and further expansion of the smoke and the temperature layer upstream of the fire location in the Greek case, while the operation of mechanical ventilation remains in both methods the same.

Furthermore, figs 1 to 4 also illustrate the evacuation lines of the trapped users. In order to estimate the self-evacuation process of trapped users, methods' common standardization is followed.

The accident scenarios assume uniform traffic. Thus, five vehicles, including the HGV that sparked the accident, are trapped in the tunnel having a $10 \mathrm{~m}$ interval among them. Each vehicle is assumed to carry an average of two passengers. It is further assumed that $100 \mathrm{sec}$ elapse from the start of the fire for all trapped users to realize the criticality of the event and start the self-evacuation process moving towards the nearest emergency exit, located at $1,200 \mathrm{~m}$ from the entrance of the tunnel. Moreover, methods' common standardizations for the movement of trapped users in a fire environment are used.

Examined users are those trapped at points: $1,500 \mathrm{~m}, 1,480 \mathrm{~m}$ and $1,460 \mathrm{~m}$ from the entrance of the tunnel. The time (duration) in which users of each method are coming out of smoke environment is depicted in fig. 5. Due to the increasing smoke propagation in the Greek method in contrast with the French one, users' moving velocities decrease and as a result their evacuation process is hindered. This significant increase in time in which users in Greek method stay in the smoke environment in contrast with those in French method is estimated with regard to fig. 5 for the first, second and third evacuation line at $11 \mathrm{sec}$, at $16 \mathrm{sec}$ and at $14 \mathrm{sec}$, respectively.

Concurrently, trapped users are crossing a high temperature environment. In order to estimate the effects of it, the Fractional Effective Dose (FED) is used. FED is defined for estimating the aggregate time until the neutralization of a user in the Greek method, whereas the French method does not mention the way of 


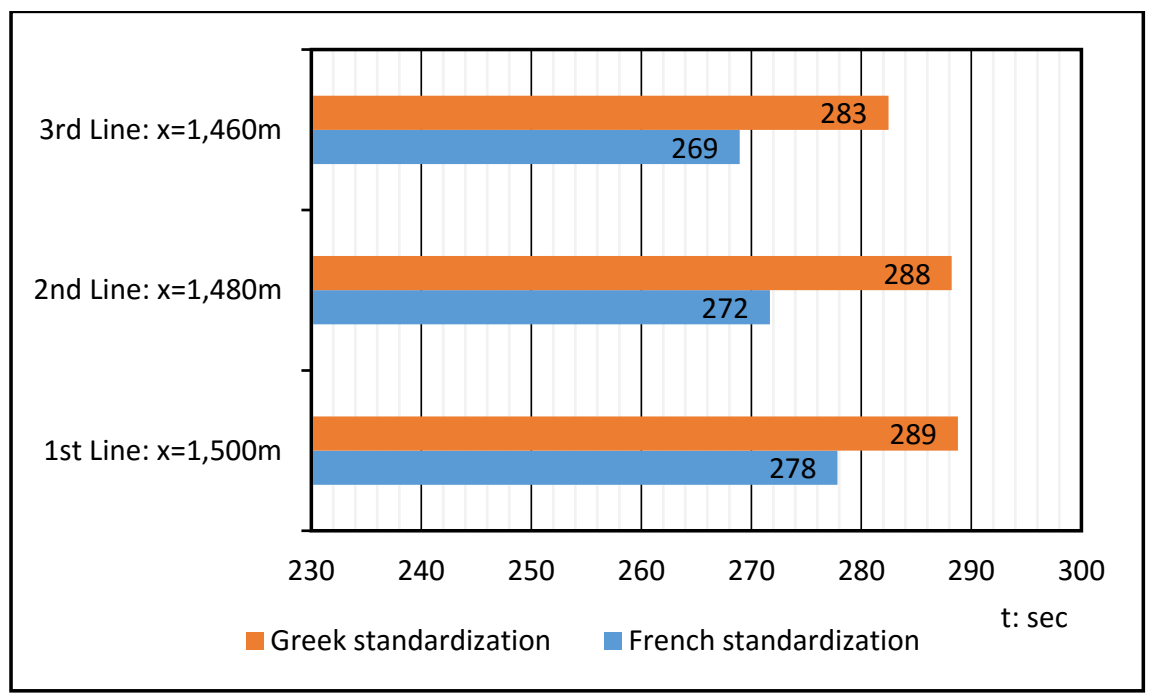

Figure 5: Users' stay into smoke cloud.

estimating the consequences of temperature on users. Thus, based on fig. 4 of the Greek method, all the users pass through an environment of at least $200^{\circ} \mathrm{C}$.

Using eqns (1) and (2) for FED calculation for convective heat accumulate per minute:

$$
\begin{gathered}
\mathrm{t}_{\text {iconv }}=\left(5^{*} 10^{7}\right) * \mathrm{~T}^{-3.4}: \text { for light clothing } \\
\mathrm{FED}_{\text {iconv. }}=\Sigma\left(1 / \mathrm{t}_{\text {iconv. }}\right) * \Delta \mathrm{t}
\end{gathered}
$$

where $\{\mathrm{t}\}$ the time in minutes and $\{\mathrm{T}\}$ the temperature in ${ }^{\circ} \mathrm{C}$ and with the obligation of $\mathrm{FED}<0.30$, is estimated that a user could tolerate approximately 13.50sec in an environment of $200^{\circ} \mathrm{C}$ until his neutralization. Hence, all trapped users in the Greek method are to be neutralized. On the other hand, based on fig. 2 of the French method, besides the first user who stays in high temperatures, the next two at $1,480 \mathrm{~m}$ and at $1,460 \mathrm{~m}$ belong in an environment of approximately $150^{\circ} \mathrm{C}$ and through FED calculation, a time space of $54 \mathrm{sec}$ is estimated. As a result, the successful ending for the evacuation of those is more than possible.

To sum up, from the risk assessment process regarding the opacity and temperature figures of fire scenarios along with the estimated self-evacuation process of trapped users is concluded a quite different estimated level of safety between the two methods.

\section{Conclusion}

The establishment of a single framework that the current legislation has already imposed in order to enhance the level of safety in road tunnels is a necessary step 
but not a sufficient condition, so far. The use of different risk assessment methods based on the diversity of the existing normative provisions which every Member State has imposed could affect the perceived level of tunnels' safety.

The effects could be seen, when by the use of two different but very similar assessment methods, the French and the Greek one, it is derived that only a small difference in the standardized fire scenario could lead to the estimation of significant more losses during the self-evacuation process of trapped users and as a consequence in significant divergence in the estimated level of safety. Thus, the same reference tunnel studied under two different, although highly similar, methods (Greek and French), can provide results which end up to a significant different in the perceived safety of the tunnel.

It is concluded here that an effort towards the homogenization of the methods used for road tunnel risk analysis across EU Member States would be very important.

\section{References}

[1] Beard, A. \& Carvel, R., The Handbook of Tunnel Fire Safety, Thomas Telford: London, pp. 13-18, 2004.

[2] Voeltzel, A. \& Dix, A., A comparative analysis of the Mont Blanc, Tauern and St. Gotthard tunnel fires. Routes/Roads magazine, 324(10), pp. 1834, 2004.

[3] European Parliament and the Council, Directive 2004/54/EC on minimum safety requirements for tunnels in the trans-European road network, European Parliament: Brussels, 2004.

[4] Word Road Association, Risk Analysis for Road Tunnels, PIARC: Paris, 2008.

[5] Word Road Association, Current Practice for Risk Evaluation for Road Tunnels. PIARC: Paris, 2008.

[6] Beard, A., Fire safety in tunnels, Fire Safety Journal, 44(8), pp. 276-278, 2009.

[7] Tunnel Study Center, Guide to Road Tunnel Safety Documentation: Specific Hazard Investigation - Booklet 4, France: Paris, 2003.

[8] Administrative Authority of Tunnels, Risk Analysis Method without considering vehicles carrying Dangerous Goods/scenario-based approach, Greece: Athens, 2011.

[9] Saunders, M., Lewis, Ph. \& Thornhill, A., Research methods for business students, Prentice Hall: Milan, 2009.

[10] Vincent, F., Ponticq, X., Mos, A. \& Burkhart, J.F., Camatt 2.0: Users' Guide, Tunnels Study Center: Paris, 2011. 